\title{
FON DUSHANBE CATALOGUE. RESULTS OF PROCESSING IN THE TYCHO-2 SYSTEM
}

\author{
G. Kokhirova ${ }^{1}$, H. Relke ${ }^{2}$, Q. Yuldoshev ${ }^{3}$, Yu.I. Protsyuk ${ }^{4}$, V.M. Andruk ${ }^{5}$ \\ ${ }^{1}$ Institute of Astrophysics of the National Academy of Sciences of Republic of \\ Tajikistan, 22,Bukhoro Street, 734042 Dushanbe, Tajikistan \\ ${ }^{2}$ Walter-Hohmann-Observatory, 159 Wallneyer St., 45133 Essen, Germany, \\ helena_relke@yahoo.com \\ ${ }^{3}$ Ulugh Beg Astronomical Institute of the Uzbekistan Academy of Sciences, \\ 33 Astronomicheskaya str., 100052 Tashkent, Uzbekistan, q.astrin@gmail.com \\ ${ }^{4}$ Research Institute Mykolaiv Astronomical Observatory, \\ 1 Observatorna Str., 54000, Mykolaiv, Ukraine, yuri@nao.nikolaev.ua \\ ${ }^{5}$ Main Astronomical Observatory of National Academy of Sciences, \\ 27 Akad. Zabolotnogo St., 03143, Kyiv, Ukraine, andruk@mao.kiev.ua
}

\begin{abstract}
In the Tycho- 2 catalogue system the processing of 1529 photographic plates of the FON Dushanbe project from the collection of the Institute of Astrophysics of the National Academy of Sciences of Tajikistan was completed. The photographic plates with the size of $8^{\circ} \times 8^{\circ}(30 \times 30$ $\mathrm{cm})$ were exposed in the zones from $-8^{\circ}$ to $+84^{\circ}$ in the period of 1985-1992 years. In years 2017 - 2020 the plates were digitized using a Microtek ScanMaker 1000XL Plus scanner with the resolution of $1200 \mathrm{dpi}$, so the size of the digitized images is near $13000 \times 13000$ px. Based on the results of the processing of digitized images a catalogue of equatorial coordinates $\alpha, \delta$ and B-magnitudes of stars for the northern hemisphere of the sky was created. The catalog contains about 30 million stars and galaxies for the epoch 1988.74. The average internal accuracy of the catalogue for all objects is $\sigma \alpha \delta= \pm 0.32^{\prime \prime}$ and $\sigma \mathrm{B}= \pm 0.11^{\mathrm{m}}$ (for stars in the range of $\mathrm{B}$ $=8^{m}-14^{m}$ the errors are $\sigma \alpha \delta= \pm 0.19^{\prime \prime}$ and $\sigma \mathrm{B}= \pm 0.07^{m}$ ) for equatorial coordinates and B-magnitudes respectively. The convergence between calculated and reference positions from the Tycho- 2 catalogue is $\sigma \alpha \delta= \pm 0.07$ " and the convergence with photoelectric B-magnitudes is $\sigma \mathrm{B}= \pm 0.16^{m}$. Five astronomical institutions took part in the processing of the photographic plates and in the creating of the FON-Dushanbe catalogue: Institute of Astrophysics of NAS of Tajikistan; Walter Hohmann Observatory, Essen, Germany; Ulugh Beg Astronomical Institute UAS, Uzbekistan; Research Institute "Mykolaiv Astronomical Observatory", Ukraine and Main Astronomical Observatory NASU, Ukraine.
\end{abstract}

Keywords: scanning, processing of digitized plates, FON project, astrometry, photometry, data analysis, stellar data catalogs

АНОТАЦІЯ. В системі каталога Тусhо-2 закінчено обробку 1529 платівок за програмою ФОН-Душанбе із колекції Інституту астрофізики АН республіки Таджикистан. Платівки з робочим полем розміром $8^{\circ} \times 8^{\circ}$ були експоновані в зонах від $-8^{\circ}$ до $+84^{\circ}$ в період
1985-1992 pр. Астронегативи були оцифровані в 20172020 pp. на сканері Microtek ScanMaker 1000XL Plus 3 просторовим розрізненням $1200 \mathrm{dpi}$, розмір платівок 30х30 см або біля 13000х13000 пкл.

За результатами обробка оцифрованих платівок створено каталог екваторіальних координат $\alpha, \delta$ i Bвеличин зір для північної півкулі неба. Каталог нараховує біля 30 млн. Зір та галактик до В $\leq 17.2^{\mathrm{m}}$ на епоху 1988.74 p. Внутрішня точність каталога для всіх об'єктів складає $\sigma_{\alpha \delta}= \pm 0.32 "$ та $\sigma_{\mathrm{B}}= \pm 0.11^{\mathrm{m}}$ (для зір в інтервалі $\mathrm{B}=8^{\mathrm{m}}-14^{\mathrm{m}}$ похибки рівні $\sigma_{\alpha \delta}= \pm 0.19$ " та $\sigma_{\mathrm{B}}=$ $\left.\pm 0.07^{\mathrm{m}}\right)$ для екваторіальних координат і зоряних Ввеличин відповідно. Сходимість між обчисленими авторами та опорними положеннями складають $\sigma_{\alpha \delta}=$ \pm 0.07 ", а сходимість з фотоелектричними зоряними Ввеличинами дорівнює $\sigma_{\mathrm{B}}= \pm 0.16^{\mathrm{m}}$. В обробці платівок і створенні каталога ФОН-Душанбе приймали участь п’ять астрономічних закладів: Інститут астрофізики АН Республіки Таджикистан, Обсерваторія ім. Вальтера Хоманна в Ессені (Німеччина), Астрономічний інститут ім. Улугбека АН Республіки Узбекистан, НДІ "Миколаївська астрономічна обсерваторія (Україна) та Головна астрономічна обсерваторія НАН України.

Ключові слова: сканування, обробка оцифрованих платівок, програма ФОН, астрометрія, фотометрія, аналіз даних, каталоги зоряних даних.

\section{Introduction}

The plan of the photographic survey of the northern sky (FON) was proposed in 1976 in Golosiiv observatory (now Main astronomical observatory NAS of Ukraine) by I.G.Kolchinsky and A.B.Onegina [Kolchinsky, 1977]. It was a very demanding project for that time and very well thought out. The northern sky must be photographed by six identical astrographs with aperture $40 \mathrm{~cm}$ and focal length 2 or $3 \mathrm{~m}$ from different observatories. Each photo- 
graphic plate should be recorded with two exposures: short exposure for accurate measurement of the stars until 12 magnitude and long one to achieve the stars of 15-16 magnitude. As the first step in the realization of FON project only the stars of the short exposure could be measured. At the beginning of the 80th years of the last century the measuring of all stars until 15-16 magnitude was not feasible. In 1982 six observatories of the former USSR: Main Astronomical (Golosiiv) observatory of Ukraine, Zvenigorod observatory of Russia, Hissar observatory of Tadjikistan, Abastumani observatory of Georgia, Zelenchuk observatory of Russia and Kitab observatory of Uzbekistan had started systematic observations with the FON project and finished it until 2000 [Pakuliak et al., 2016, Andruk et al., 2017b]. Each observatory photographs entire north sky independently, so at the end of the observations each observatory will have its own collection of the glass plates. The FON project was one of the last photographic surveys of the past century. Currently progress in information technologies made possible to do that was not realistic at the beginning of 80th years of the last century. The modern scanners, computers and software give pulse to scan photographic plates and then to reduce the digitized images. The photographic plates of the FON project could be processing now. So in 2016 on the basis of data of 2260 digitized plates from the glass collection of Double Wide-angle Astrograph (DWA) MAO NAS of Ukraine the catalogue of positions and B-magnitudes of objects in the zone of DE from -4 to +90 degrees was created [Andruk et al., 2015, 2016a; 2016b]. Then in 2017 the processing of 1963 photographic plates of the Kitab part of the FON project in the zone of DE from -20.5 to +2.5 degrees was finished. The catalogue of positions and B-magnitudes of 13.4 million objects brighter than $\mathrm{B} \leq$ $17.5^{\mathrm{m}}$ for the mean epoch 1985.0 was created. [Yuldoshev et al., 2017a, 2017b] The creating of the FON Dushanbe catalogue is the next important step in the realization of the FON project. Unfortunately, not all observatories could finish the observation and continue works within the FON project. So regular observations in Hissar observatory were started in 1985 by the observing team $(\mathrm{H}$. Relke, O. Gamburg, M. Tsigankova, N. Kiselev und A. Mullo-Abdolov) and were interrupted in 1992 due to unstable political situation in Tajikistan. During this time 1560 photographic plates were exposed. For the long time this valuable collection of the glass plates was standing on the shelfs and waiting for processing. Finally the time has come. In 2017 Institute of Astrophysics has begun the digitizing of the photographic plates of the FON project.

\section{Digitization of the photographic plates of the Du- shanbe part of the FON project}

In 2017 thanks to the support of the NAS of Tajikistan the Institute of Astrophysics acquired a professional scanner Microtek ScanMaker 1000XL Plus with the resolution of $1200 \mathrm{dpi}$, which allows a scanning the photographic plates with the size of $30 \times 30 \mathrm{~cm}\left(8^{\circ} \times 8^{\circ}\right)$. The size of the digitized images is $13000 \times 13000 \mathrm{px}$. The investigation of the astrometric and photometric characteristics of the Microtek ScanMaker 1000XL Plus scanner was done in 2017 [Mullo-Abdolov et al., 2017, 2018; Rahimi et al., 2018].
The results of the performed work allowed making the following conclusion: within the precision of reduction of photographic plates the scanner is suitable for the performing of astrometric and photometric works for the terrestrial astronomy and in particular for the FON project. Errors of one measurement are 0.1 arc seconds for the equatorial coordinates and $0.04^{\mathrm{m}}$ for the B-magnitudes. The errors of star image center estimation is $\sigma_{x y}= \pm 0.054$ px. The errors are given for stars brighter than $B=13.5^{\mathrm{m}}$. The insertion errors of scanner in photometric estimations has been found as $\sigma_{\mathrm{m}}= \pm 0.020^{\mathrm{m}}$. With the help of the scanner 1560 photographic plates of the FON glass collection of the Institute of Astrophysics were digitized by A. Mullo-Abdolov. The first results of the processing of 71 scans in the zero declination zone and 58 scans from the declination zones 64, 68 and 72 degrees give the positional accuracy $\sigma_{\mathrm{RA}, \mathrm{DE}}=0.33$ " for stars in the magnitude range from $5^{\mathrm{m}}$ to $17^{\mathrm{m}}$. The photometric accuracy has occurred to be $\sigma_{B}=0.12^{\mathrm{m}}$. The convergence between calculated and Tycho-2 reference positions of objects is $\sigma_{\mathrm{AC}, \mathrm{DE}}=0.12$ ", while photometric one is $\sigma_{\mathrm{BT}}=0.19^{\mathrm{m}}$. The convergence with photoelectric data is $\sigma_{\mathrm{B}}=0.14^{\mathrm{m}}$. In 2018 -- 2019 270 plates of the declination zones 4, 20 and 36 degrees were processed by H.Relke and used for the searching of asteroids and commets by O. M. Yizhakevych and S.V.Shatokhina [Shatokhina et al., 2018, 2020; Yizhakevych et al., 2018]. In 2020 the digitizing of all photographic plates was finished and the scans were sent to colleagues, who desided to help Institute of Astrophysics in the processing of scans: H.Relke of the Walter Hohmann Observatory, Essen, Germany; Q. Yuldoshev of the Ulugh Beg Astronomical Institute UAS, Uzbekistan; Yu. Protsyuk of the Research Institute "Mykolaiv Astronomical Observatory" and V. Andruk of the Ukraine and Main Astronomical Observatory NASU, Ukraine. The plates were divided by zones and processed in 2021: the declination zones 12, 28, 44 and 60 degrees were processed by $\mathrm{Yu}$. Protsyu, the zones 08, 24 and 40 degrees by Q. Yuldoshev, the zones -08, 4, 16, 20, 32, 36, 48, 52 and 56 degrees by $\mathrm{H}$. Relke and the zones $-4,0,64$, $68,72,76,80$ and 84 by degrees V.Andruk.

\section{Astrometric and photometric solution}

Astrometric reduction of the digitized photographic plates with the size of $8 \times 8$ degrees is carried out in two steps: the investigation of the systematic errors of the scanner $\Delta \alpha$ and $\Delta \delta$ and then the reduction of rectangular coordinates $\mathrm{X}, \mathrm{Y}$ of all objects in the system of equatorial coordinates $\alpha, \delta$ of Tycho-2 catalogue. At the both steps of data processing the tangential coordinates $\xi, \eta$ are calculated by the method of the smallest squares using the formula

$$
\begin{gathered}
\xi=a+a X f+a Y f+a R m+a f+\Sigma b \quad X / Y m, \\
(l=0 \div 6, m=0 \div 6, l+m=n, n=1 \div 6) \\
\eta=c+c X f+c Y f+c R m+c f+\Sigma d X / Y m, \\
(l=0 \div 6, m=0 \div 6, l+m=n, n=1 \div 6)
\end{gathered}
$$


where $\mathrm{i}=1,2, \ldots \mathrm{N}$ - number of stars from the TYCHO-2 catalogue on the digitized plate; $\mathrm{Xi}$, Yi и $\mathrm{Ri}$ - coordinates and distances of star images relative to the plate center; mi - instrumental photometric star values; fi - diameters of star images; coefficients a2, a3, a4 and c2, c3, c4 are responsible for the coma; coefficients a5, c5 - take into account the influence of the brightness equation (these coefficients are calculated separately); the $b_{1 m}$ and $d_{1 m}$ are the coefficients of the full polynomial of sixth order (altogether 27 members), which in a general case, describe optical aberrations of the telescope complicated by systematic errors of the scanner. As was mentioned above all photographic plates of the FON project was obtained with two exposures of different durations shifted by both coordinates. The aim was to restore the characteristic curve for photometric determinations as a compiled one from two exposures in order to achieve the same accuracy for stars on the entire range of magnitudes. The astrometric and photometric solution was developed by V. Andruk and described in following publications [Andruk et al., 2015, 2017a; Yuldoshev et al., 2017, 2019].

\section{Creating of the FON-Dushanbe catalogue}

To create the catalog the following was done. For individual zones with a height of $\pm 2^{\circ}$ from the center the principle of overlapping in declination $\delta$ is implemented. Within the individual zones the overlapping is performed with the offsets of centers relative to each other by approximately $8 \% \cos \delta$ in right ascension $\alpha$. The centers of the zones are separated from each other by $4^{\circ}$ on $\delta$. The number of plates for the individual zones are given in Table 1 .

Table 1. Numbers of plates over the zones from $-8^{\circ}$ to $84^{\circ}$ in declination.

\begin{tabular}{|l|l|l|l|l|l|l|l|l|}
\hline zone & -8 & -4 & 0 & 4 & 8 & 12 & 16 & 20 \\
\hline plates & 41 & 45 & 71 & 70 & 69 & 80 & 85 & 85 \\
\hline
\end{tabular}

\begin{tabular}{|l|l|l|l|l|l|l|l|l|}
\hline zone & 24 & 28 & 32 & 36 & 40 & 44 & 48 & 52 \\
\hline plates & 84 & 88 & 89 & 90 & 89 & 90 & 92 & 90 \\
\hline
\end{tabular}

\begin{tabular}{|l|l|l|l|l|l|l|l|l|}
\hline zone & 56 & 60 & 64 & 68 & 72 & 76 & 80 & 84 \\
\hline plates & 90 & 90 & 19 & 9 & 21 & 20 & 11 & 11 \\
\hline
\end{tabular}

In total 1529 plates were completely processed. In these zones about 112.66 million objects of various natures were registered. After the analysis and comparing with the UCAC4 catalog the equatorial coordinates and B values were obtained for about 30 million stars and galaxies up to $\mathrm{B} \leq 17.2^{\mathrm{m}}$ on the middle epoch of observation 1988.74. Figure 1 shows a sky map for the stars $B=10^{\mathrm{m}}$, built on the base of the results of processing of the FON-Dushanbe plates. The photometric system of the FON-Dushanbe catalog is shown in Figure 2. Figure 3 shows the trend of errors for the stars measured at least twice. The erros of the aquatorial coordinates $\sigma \alpha \delta$ with magnitude $\mathrm{B}$ are presented on panels a and $\mathrm{b}$. Panels $\mathrm{c}, \mathrm{d}$ show the trend of errors in determining of the $\sigma \mathrm{B}$ magnitudes relative to the magnitudes and diameters of the images of objects $f_{1 / 2}$. The lower panel $f$ shows a distribution of the number of objects relative the B-magnitudes of the FON Dushanbe catalog. The internal accuracy of the catalog for all objects is $\sigma \alpha \delta= \pm 0.32 "$ and $\sigma \mathrm{B}= \pm 0.11^{\mathrm{m}}$ for equatorial coordinates and B-magnitudes respectively. For stars in the interval of $\mathrm{B}=8^{\mathrm{m}}-14^{\mathrm{m}}$ the errors are $\sigma \alpha \delta= \pm 0.19^{\prime \prime}$ and $\sigma \mathrm{B}= \pm 0.07^{\mathrm{m}}$. The convergence between the calculated by the authors and the reference positions of the Tycho- 2 catalog is $\sigma \alpha \delta= \pm 0.07 "$, and the convergence with the photoelectric B-magnitudes is $\sigma \mathrm{B}= \pm 0.16^{\mathrm{m}}$.

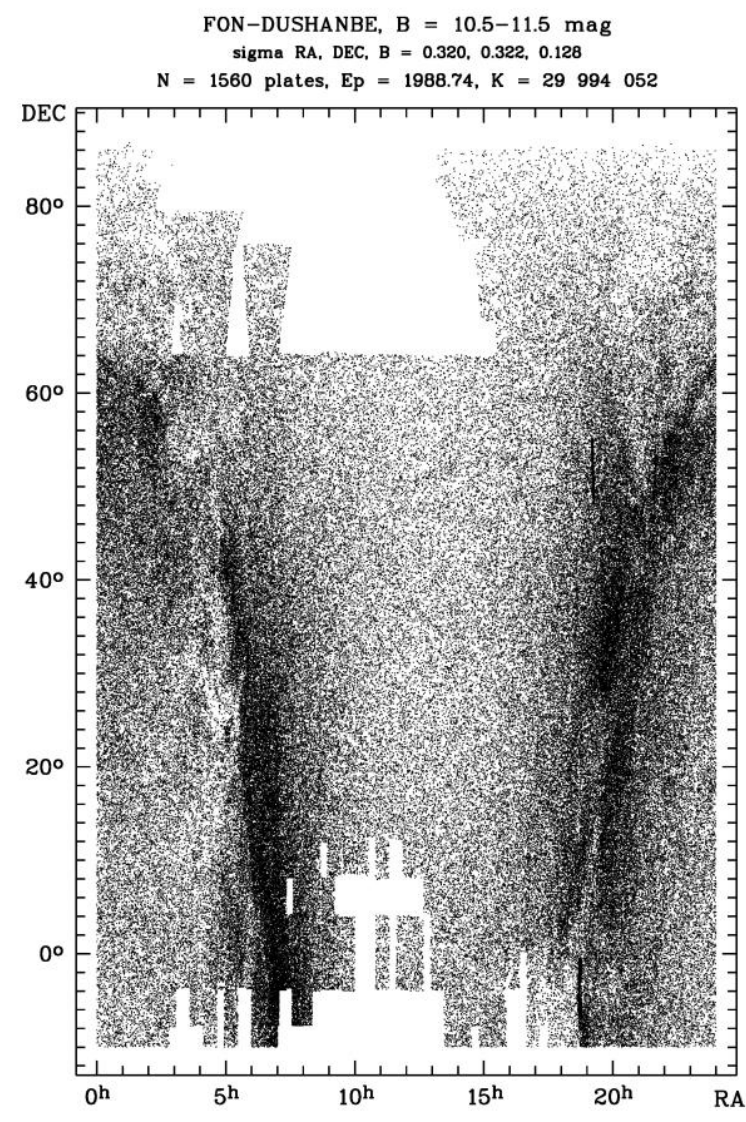

Figure 1: A sky map for the stars $B=10^{\mathrm{m}}$ constructed from the results of processing the FON-Dushanbe plates. In total, the catalog contains about 30 million objects. The middle epoch of the catalog is 1988.74

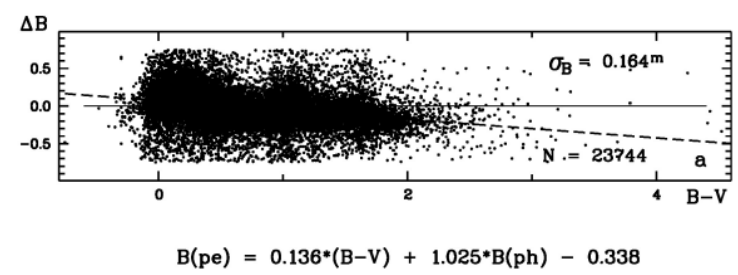

Figure 2: Photometric system of the FON-Dushanbe catalog. Results of comparing the B-values of the catalog with photoelectric measurements of Bpe stars. The course of the differences $\sigma \mathrm{B}=\mathrm{B}-\mathrm{Bpe}$ relative to the color indices of the $\mathrm{B}-\mathrm{V}$ stars is shown. 

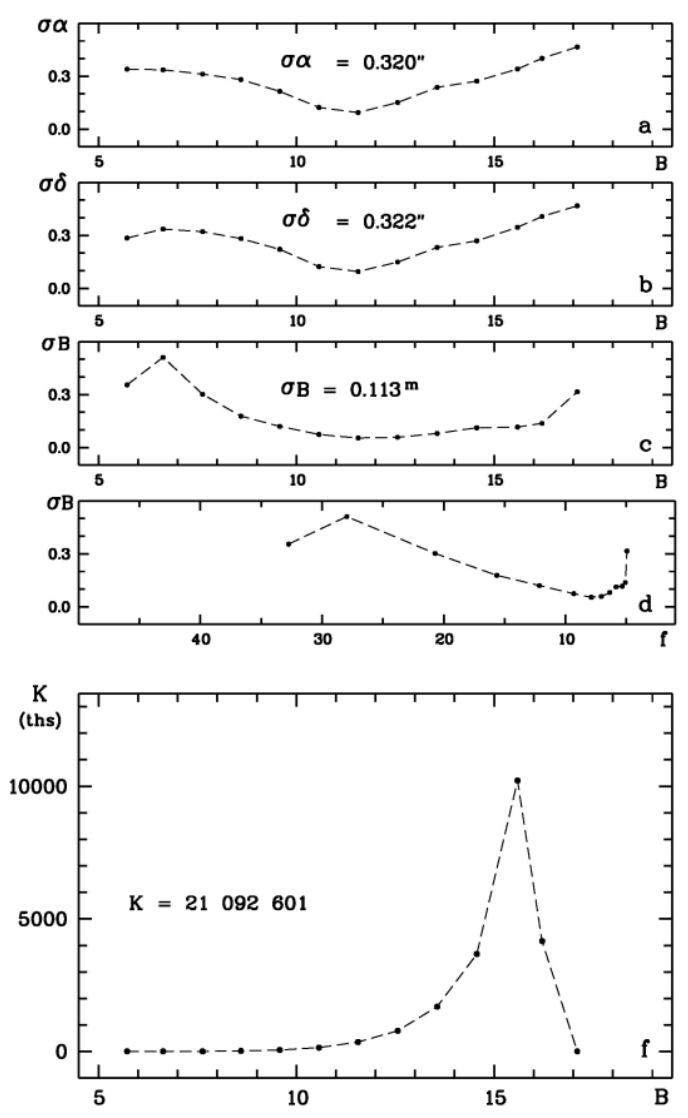

Figure 3: The course of errors in the catalog for determining the equatorial coordinates $\sigma \alpha \delta$ with magnitude B (panels a and b). Panels c, d show the course of errors in determining the magnitudes of $\sigma \mathrm{B}$ relative to the magnitudes and diameters of the objects' images. The lower panel $\mathrm{f}$ shows a distribution of the number of objects relative B-magnitudes of the catalog.

\section{Conclusion}

The coordinates of stars and galaxies were obtained in the Tycho-2 catalogue system on the mean epoch of observation 1988.74. B-values were calculated in the photoelectric standard system [Relke et al., 2015]. The catalog of the positions and B-magnitudes of the stars of the Dushanbe part of the FON program will be posted on the web pages of the Main Astronomical Observatory NAS Ukraine, UkrVO [Vavilova et al., 2012, 2016, 2017] and of the Institute of Astrophysics of the NAS of Tajikistan. The catalog for about 30 million stars and galaxies up to $\mathrm{B} \leq 17.5 \mathrm{~m}$ includes the equatorial coordinates $\alpha, \delta$ for the individual observation epoch and the equinox 2000.0, magnitudes in system B, as well as errors in determining of these values, the number of determinations of each star or galaxy and information in the form of intensity values Ic at the center of measured object and the averaged values for diameters $\mathrm{f}_{1 / 2}$ of each stellar image. The catalog also includes additional information on proper motions and $\mathrm{f}, \mathrm{B}, \mathrm{V}, \mathrm{r}$, i magnitudes from the UCAC4 catalog [Zakharias et al., 2013]. It is planned to create a version of the catalog in the GAIA DR2 system. The authors hope that the catalogs of the FON project will be useful in the search for disappeared objects or other transient processes that have occurred in the starry sky [Villarroel et al., 2021].

Acknowledgements. The Institute of Astrophysics is thankful to the colleagues V.Andruk, H.Relke, Yu. Protsyuk, Q. Yuldoshev for the help in the processing of the scans, calculations and creating of the FON Dushanbe catalogue as well as to A. Mullo-Abdolov for the keep of the glass collection of the Dushanbe part of the FON project.

\section{References}

Andruk V.M., Pakuliak L.K., Golovnia V.V. et al.: 2015, Odessa Astron. Publ., 28, 192.

Andruk V.M., Golovnia V.V., Ivanov G.A. et al.: 2016, Kinem. Phys. Cel. Bodies, 32, N1, 38.

Andruk V.M., Pakuliak L.K., Golovnia V.V. et al.: 2016, Kinem. Phys. Cel. Bodies, 32, N5, 260.

Andruk V.M., Pakuliak L.K., Golovnia V.V. et al.: 2017, Scince and Innovation, 13a, 17.

Andruk V., Yuldoshev Q., Eglitis I. et al.: 2017, Odessa Astron Publ., 30, 159.

Kolchinsky I.G., Onegina A.B.: 1977, Astrometry and Astrophysics, 33, 11.

Mullo-Abdolov A., Kokhirova A., Relke H. et al.: 2017, Odessa Astron Publ., 30, 186.

Mullo-Abdolov A., Relke H. Kokhirova A.,et al.: 2018, Odessa Astron Publ., 31, 224.

Pakuliak L.K., Andruk V.M., Golovnia V.V. et al.: 2016, Odessa Astron. Publ., 29, 132.

Rahimi F., Mullo-Abdolov A.Sh., Kokhirova G.I. et al.: 2018, Reports AS RT, 60, No2, 144.

Relke E., Protsyuk Yu.I., Andruk V.M.: 2015, Odessa Astron. Publ., 28, 211.

Shatokhina S.V., Kazantseva L.V., Yizhakevych O.M., Andruk V.M.: 2018, Kinem. Phys. Cel. Bodies, 34, N5, 70.

Shatokhina S.V., Relke H.V., Mullo-Abdolov A.Sh.,. et al.: 2020, Odessa Astron. Publ., 33, 154.

Vavilova I.B., Pakuliak L.K., Protsyuk Yu.I., et al.: 2012, Baltic Astronomy, 21, N3, .356.

Vavilova I.B.: 2016, Odessa Astron. Publ., 29, 109.

Vavilova I.B., Yatskiv Ya.S., Pakuliak L.K.: 2017, IAUS, 325, 361.

Villarroel B., Marcy G.W., Geier S., et al.; 2021, NatSR, $1112794 \mathrm{~V}$.

Yizhakevych O.M., Mullo-Abdolov A.Sh., Relke H.V. et al.: 2018, Odessa Astron. Publ., 31, 247.

Yuldoshev Q.X., Ehgamberdiev Sh.A., Muminov M.M. et al.: 2017, Kinem. Phys. Cel. Bodies, 33, N5, 250.

Yuldoshev Q., Protsyuk Y., Relke, H. et. al., 2019, Astronomische Nachrichten, 340, 6, 494.

Zacharias N., Finch C.T., Girard T.M. et al.: 2013, Astron. J., 145, N2. -44Z. -14p. 